\title{
The using of ion exchange method of Urban Territories' sub-surface waters purification in Sakha (Yakutia)
}

\author{
Svetlana Fedorova ${ }^{1, *}$ and Anatolii Kryzhanovsky ${ }^{2}$ \\ ${ }^{1}$ Institute of Siberian Branch of the Russian Academy of Sciences, Russian Federation, 677010, \\ Yakutsk \\ ${ }^{2}$ Novosibirsk State University of Architecture and Civil Engineering, 630099 Novosibirsk, Russia
}

\begin{abstract}
The urgency of the conducted studies is dictated by the problem of Urban Territories' sub-surface waters purification providing in the Republic of Sakha (Yakutia) population with drinking water, which can be partly solved by involving the subsurface waters of the Yakutian artesian basin in the domestic and drinking water supply systems. The chemical composition feature of the under-ground waters under consideration, which substantially complicates their widespread use for domestic and drinking purposes, is the increased content of lithium, fluorine and sodium.

The main research objective is to develop an effective method for clearing the sub-permafrost waters of the Yakutian artesian basin from lithium compounds, which can be used in water treatment systems for domestic and drinking purposes. As a result of the experimental studies on the sub-permafrost water purification of casting by the ion exchange method, its content reduced from 0.5 to $0.01 \mathrm{mg} / 1$, which fully met the requirements for drinking water. On the basis of the results obtained, a comprehensive scheme for the sub-permafrost waters purification of the Yakutian artesian basin from lithium, fluorine and sodium was developed for the purpose of household and drinking water supply.
\end{abstract}

\section{Introduction}

The problem of providing the Republic of Sakha (Yakutia) population with drinking water taking into account harsh climatic conditions is extremely urgent. The uneven distribution of the population over the vast territory of the republic dictates its requirements for the water supply organization. In many settlements of Yakutia, the organization of water

\footnotetext{
* Corresponding author: michmacha@mail.ru
} 
supply from surface sources is impossible due to their insignificant water availability or remote location. Therefore, the issue of water supply organization to the population of Central Yakutia due to sub-permafrost waters use of the Yakutian artesian basin is very topical and promising. These waters have a stable chemical composition that does not undergo seasonal changes; they are reliably protected from anthropogenic impact and are safe in radiological and bacteriological terms. The use of regionally distributed groundwater will make it possible to maximize the supply of water to specific water users, which will significantly reduce the cost of organizing and operating drinking water supply systems.

Lithium is widely distributed in nature, it is found in many rocks, soils, salt brines and sea water. At the same time, its concentration is insignificant, and therefore lithium belongs to the group of rare metals. In nature it is found only in the form of compounds, concentrated mainly in acidic igneous and sedimentary rocks, the content of lithium averages $6.5 * 10-3 \%$. Clark of lithium in the sea water is $0.17 * 10-4 \%$, in river waters $2.5 * 10-7 \%$, in living matter $-1.0 * 10-5 \%$ (Chertko \& Chertko, 2008). Lithium belongs to the first group of the elements' periodic system and heads a subgroup of alkali metals. It is the lightest metal with a density of $0.534 \mathrm{~g} / \mathrm{sm} 3$ (Ostroushkoetal, 1960). Lithium is a typical lithophilic element; it is closely associated with sodium, fluorine, beryllium and boron (Landolt \& Sittig, 1961). Lithium has the smallest atomic radius, and, consequently, the largest ionization potential. Chemically, it is less active than other alkali metals.

Despite the considerable reserves of groundwater, their use in domestic and drinking water supply systems is limited due to the high content of fluorine, lithium and sodium. Deviation from the norms for the content of the listed elements is caused by the geological structure, permafrost-hydrogeological conditions and the lithological composition of the water-bearing rocks.

The choice complexity of the technological scheme for water purification is determined by the presence of natural origin lithium in water, which content considerably exceeds the maximum allowable concentrations for domestic and drinking water supply.

Lithium is widely applied in metallurgy, in the laser electronic and nuclear industry, as well as in medicine. The mechanism of the lithium action on the nervous system from the point of clinical medicine view is quite well studied. Lithium preparations are used as a normotimic and psychotropic agent for the treatment of severe mental illness. Nevertheless, despite the proven therapeutic effect of lithium drugs, their use in clinical practice is very limited due to a number of side effects, including cardiovascular, thyroid and genitourinary disorders (Dmitrieva, 2009).

Despite of the fact the proportion of lithium in the sub-permafrost waters is insignificant; its content is tens of times higher than the maximum allowable concentrations established for domestic and drinking water. Therefore, the use of the groundwater under consideration for domestic and drinking purposes is possible only after preliminary water treatment.

The use of widely used reverse osmosis plants for water purification is not effective against lithium and leads to significant production losses of water. Long-term experience of their operation in Yakutsk shows that the producers receive not more than $50 \%$ purified from the total volume of the selected water.

The earlier published materials contain information on the extraction of lithium from various solutions and brines for industrial purposes, while there is no information on water treatment systems for domestic and drinking purposes that allow reducing the lithium content. The existing methods of extracting lithium from natural brines and technological solutions for industrial purposes belong to the field of hydrometallurgy. They include various combinations of extraction methods, evaporation, sorption and electrolysis, as well as other physico-chemical methods using chemicals and reagents that are not compatible 
with domestic drinking water supply systems. An analysis of the water purification methods used to date has suggested the effectiveness of lithium removal by ion exchange.

The main research goal is the methods development for purification of the subpermafrost waters of the Yakutian artesian basin from lithium compounds.

To achieve this goal requires the following tasks' solutions:

1) collection, systematization and generalization of hydrochemical data on the lithium distribution extent and nature in the underground waters of the Sakha (Yakutia) Republic;

2 ) analysis of water treatment existing methods and conducting experimental studies to assess the possibility of their use for water purification from lithium.

3) development of an integrated scheme for water treatment of the Yakutian artesian basin sub-frozen waters, which provides for the reduction of fluorine, lithium and sodium to standardized requirements.

The geochemical regularities features of lithium distribution in various soils are presented in A.P. Vinogradov (1957). Questions of lithium in nature distribution, its physical properties and possible connections with other elements are considered by P.E. Landolt \& M. Sittig (1961). Studies of the most important lithium minerals, geochemical and physico-chemical properties of lithium and its compounds are summarized by the team of authors in Y.I. Ostroushkoet (1960) works. The methods for obtaining lithium and the range of its application are set forth in VE. Plyushchev \& B.D. Stepin (1970). The content of lithium in the earth's crust, marine and river waters, living matter and the human body is given in N.K. Chertko \& E.N. Chertko (2008). The use of lithium salts in clinical medicine, their effects on the human body and the associated side effects are discussed in T.B. Dmitrievaet (2009) [1,3,4,9,11].

Elevated lithium concentrations in the sub-permafrost waters of Central Yakutia are noted in V.T. Balobaevetal. (2003). Features of individual chemical elements concentration in the conditions of freezing and thawing of rocks are considered N.P. Anisimova \& N.A. Pavlova (2014). Attempts to trace the change in the concentration of fluorine depending on the age and lithological rocks composition, the depth of aquifers occurrence, the chemical composition of water and the thickness of frozen rocks have been undertaken by N.P. Anisimova \& T.V. Golovanova (1972). Features of distribution and occurrence of groundwater in the permafrost province, their chemical composition and the content of individual elements, including lithium, fluorine and sodium, are presented in S.L. Shvartsev (1978) $[2,7,8,10]$.

\section{Materials and Methods}

The authors collected and systematized hydrochemical data on operational and exploratory wells located on the Republic of Sakha (Yakutia) territory. More than 300 chemical analyzes of water for 120 hydro-geological wells were processed. For each well, the most representative data on the quality of groundwater were selected, which are tabulated and sorted by administrative affiliation.

The ion exchange method approbation of water purification from lithium ions was carried out on a model non-pressure installation in the laboratory of groundwater and the cryolithozone geochemistry of the Permafrost Institute named after P.I. Melnikov Siberian Branch of Sciences Russian Academy [1].

Experimental studies were carried out on real sub-permafrost waters taken from existing water wells. A strongly acidic Na-cation ion-exchange resin HCR-S / S (Na) containing active sulfo groups were used as a filtering material. The total exchange capacity of the cation exchange resin of this brand, corresponding to the number of active ion-exchange functional groups capable of being exchanged per unit volume, is $1900 \mathrm{~g}$-eq $/ \mathrm{m} 3$. The granulometric composition is characterized by grains of monospheric type $0.6-0.8 \mathrm{~mm}$ in 
size. The filtration of groundwater through a layer of ion exchange resin loaded into a laboratory installation was carried out from the top down at a rate of 0.14 to $0.341 / \mathrm{min}$. After the exchange capacity of the Na-cationite resin was depleted, its reduction was carried out by feeding a $\mathrm{NaCl}$ regeneration solution upward through the loading layer (Fedorova \& Kryzhanovskii, 2017). [6]

\section{Results}

The results of hydrochemical data generalization are presented in Table 1 .

Table 1. Content of lithium, fluorine and sodium in the sub-permafrost waters of Central Yakutia

\begin{tabular}{|l|c|c|c|c|}
\hline $\begin{array}{c}\text { Administrative } \\
\text { District }\end{array}$ & $\begin{array}{c}\text { Mineralization, } \\
\mathrm{mg} / 1 \\
\text { (SPW 1 g / 1) }\end{array}$ & $\begin{array}{c}\text { The content of } \\
\text { lithium, mg / 1 } \\
\text { (SPW 0.03 } \\
\mathrm{mg} / \mathrm{l})\end{array}$ & $\begin{array}{c}\text { Fluoride } \\
\text { content, mg / 1 } \\
\text { (SPW 1.5 mg } \\
/ 1)\end{array}$ & $\begin{array}{c}\text { Content of } \\
\text { sodium, mg / 1 } \\
\text { (SPW 200 mg / 1) }\end{array}$ \\
\hline $\begin{array}{l}\text { Megino- } \\
\text { Kangalassky }\end{array}$ & $1,0-2,0$ & $0,16-0,8$ & $0,76-8,89$ & $149-590$ \\
\hline Churapchinsky & $0,75-1,8$ & $0,13-0,96$ & $0,25-2,29$ & $135-382,4$ \\
\hline Tattinsky & $0,9-1,2$ & $0,13-0,27$ & $3,15-3,72$ & $378,75-409,2$ \\
\hline Amginsky & $0,7-1,25$ & $0,17-0,25$ & $0,43-3,55$ & $98,25-320$ \\
\hline Ust-Aldan & $0,53-1,23$ & $0,06-0,3$ & $0,87-1,51$ & $419,5-432,8$ \\
\hline Gornyi & $0,49-0,5$ & $0,07-0,085$ & $0,19-0,44$ & $114,95-120,1$ \\
\hline Khangalassky & $0,54-1,93$ & $0,388-0,44$ & $4,26-5,87$ & $407,5-505,0$ \\
\hline C. Yakutsk & $0,95-1,8$ & $0,15-0,85$ & $2,87-12,3$ & $275-490$ \\
\hline
\end{tabular}

Systematization of information on the groundwater chemical composition was made it possible to identify the most problematic components that are typical for the regionally widespread sub-permafrost waters of the Republic. Based on the hydrochemical data analyzed, the mineralization of the sub-permafrost waters varies from 0.49 to $2.0 \mathrm{~g} / 1$, the lithium content in them is from 0.06 to $0.96 \mathrm{mg} / 1$, the fluorine from 0.19 to $12.3 \mathrm{mg} / 1$, sodium - from 98.25 to $590.0 \mathrm{mg} / 1$.

High-pressure underground waters are distributed under a permafrost layer with 150$550 \mathrm{~m}$ thickness. The aquiferous deposits are composed of terrigenous and carbonate rocks of the Jurassic and Cambrian age. Depending on the lithological composition of the waterbearing rocks, the chemical composition of the sub-permafrost waters varies from bicarbonate magnesium-sodium to sulfate-chloride-hydrocarbonate sodium.

Experimental studies on the lithium content reduction in the sub-permafrost waters were carried out by the ion exchange method in the laboratory on a model installation. After filtering the water through a layer of $\mathrm{Na}$-cationite resin, the lithium content decreased from 0.5 to $0.01 \mathrm{mg} / 1$, which did not exceed the established maximum permissible concentrations for drinking water.

Thus, the replacement reactions of lithium ions with sodium ions on $\mathrm{Na}$-cation exchange ion resin will be written as follows:

in the molecular form:

$2 \mathrm{NaR}+\mathrm{Li}_{2} \mathrm{SO}_{4} \rightarrow 2 \mathrm{LiR}+\mathrm{Na}_{2} \mathrm{SO}_{4}$

$\mathrm{NaR}+\mathrm{LiCl} \rightarrow \mathrm{LiR}+\mathrm{NaCl}$,

in the ionic form:

$\mathrm{Na}^{+} \mathrm{R}^{-}+\mathrm{Li}^{+} \rightarrow \mathrm{Li}^{+} \mathrm{R}^{-}+\mathrm{Na}^{+}$,

where $\mathrm{R}$ is a complex cationite radical not subject to dissolution in an aqueous medium.

The regeneration reaction of the Na-cation exchange ion resin in the molecular will have the form: 
$\mathrm{LiR}+\mathrm{NaCl} \rightarrow \mathrm{NaR}+\mathrm{LiCl}$.

The results of the pilot studies formed the basis for the development of the water supply project Maya village of the Megino-Kangalas district of the Republic.

As a source of water supply, the pressurized water-bearing complex of the explored Mayinsky groundwater field, characterized by a hydrocarbonate magnesium-sodium composition with a mineralization of about $1000 \mathrm{mg} / 1$, is considered as a source of water supply. Their sodium content is $194.9-202.5 \mathrm{mg} / 1$, fluorine $2.08-2.3 \mathrm{mg} / 1$, lithium 0.43 $0.50 \mathrm{mg} / 1$. The content of the main cations in the water from the well №1-M before and after the lithium removal experiments by the ion exchange method is shown in Table 2. It was established that during the ion exchange the sodium concentration is increased due to the retained hardness, lithium and strontium cations.

Table 2. Chemical composition of groundwater from well №1-M before and after ion exchange

\begin{tabular}{|c|c|c|c|}
\hline Index & SPW mg / & Initial water, mg / 1 & $\begin{array}{c}\text { Water after ion exchange, } \mathrm{mg} \\
/ 1(\mathrm{mg}-\mathrm{eq} / \mathrm{l})\end{array}$ \\
\hline \multicolumn{4}{|c|}{} \\
\hline $\mathrm{Na}^{+}$ & 200 & Cations \\
\hline $\mathrm{K}^{+}$ & - & 194,9 & 208,8 \\
\hline $\mathrm{Ca}^{2+}$ & - & 2,23 & 0,48 \\
\hline $\mathrm{Mg}^{2+}$ & 50 & 12,4 & 0,8 \\
\hline $\mathrm{Li}^{+}$ & 0,03 & 23,9 & 1,6 \\
\hline $\mathrm{Sr}^{2+}$ & 7 & 0,5 & 0,01 \\
\hline
\end{tabular}

In the natural state, the groundwaters under consideration have near-zero temperatures, so it makes it very difficult to pass chemical reactions, they are heated up to $10^{\circ} \mathrm{C}$ temperature

The basic technological scheme of water treatment, developed on the basis of studies for the Mayinsky groundwater field, is shown in Figure 1.

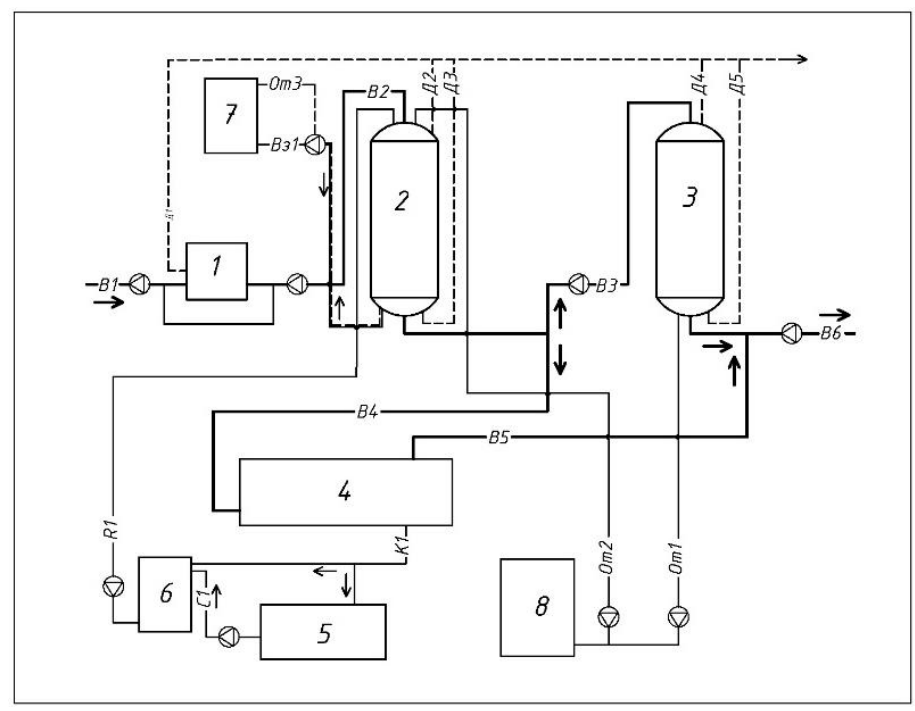

Fig. 1. Principal flow chart of water treatment: 1-disk filter; 2-ion-exchange filter; 3-filter with loading "Calcite"; 4-reverse osmosis unit; 5-tank for soaking salt; 6-tank for 
preparation of regeneration solution; 7-water for loosening the load; 8-water for washing load.

Heated water is supplied to a mechanical cleaning filter, which is designed to protect the main structures and loading materials. For the purification of groundwater from lithium, single-stage filtration is provided on ion exchange filters loaded with $\mathrm{Na}$-cationite resin. In order to reduce the content of sodium and fluorine in water, the volume part of water $(20 \%$ of the total volume) is sent to the reverse osmosis unit. The main water flow ( $80 \%$ of the total volume) is directed to vertical pressure filters with the "Calcite" loading, which will allow adjusting the water composition by the hardness salts. According to the calculations, after mixing both water flows, the concentrations of sodium and fluorine are approximately 170 and $1.3 \mathrm{mg} / 1$, respectively

\section{Discussion}

The carried out researches are directed on the decision of the major applied problem connected with maintenance of the Republic Sakha (Yakutia) population with qualitative potable water at the expense of underground waters use.

Systematization and generalization of hydrochemical data allowed assessing the scale of lithium distribution problem in the sub-surface waters of Yakutia.

The authors carried out experimental studies on the purification of the Yakutian sub-frozen waters artesian basin from lithium by ion exchange. The results of the experiments showed high efficiency with an average purification rate of $97 \%$. To determine the technical characteristics and filtration parameters of water treatment systems based on the ion-exchange method, further research on a production scale is required.

The developed basic technological scheme of water treatment in case of adaptation to specific indicators of water quality can have significant prospects for practical application.

\section{References}

1. N.P. Anisimova, T.V. Golovanova, The fluorine content in the subpermafrost waters of Central Yakutia and methods of decrease in its concentration, Ed. P.I. Melnikov, Geocryological and hydrogeological studies of Siberia, 340 (1972)

2. N.P. Anisimova, N.A. Pavlova, Hydrogeoghemical studies of permafrost in Central Yakutia, Academic Publishing House "Geo", Novosibirsk, 400 (2014)

3. V.T. Balobaev, L.D. Ivanova, N.M. Nikitina, V.V. Shepelev, N.S. Lomovtseva, V.I. Skutin, Groundwaters in Central Yakutia and prospects of their use, Novosibirsk: Publishing House of SB RAS Dranch "Geo". 400 (2003)

4. N.K. Chertko, E.N. Chertko, Geochemistry and ecology of chemical elements, Publishing House of Belarusian State University, Minsk, 300 (2008)

5. T.B. Dmitrieva, V.N. Krasnova, N.G. Neznanova, V.Y. Semke, A.S. Titanova, National manual, Publishing House "GEOTAR-Media", Moscow, 150 (2009)

6. S.V. Fedorova, A.N. Kryzhanovskii Lithium removal from underground water by ion exchange method, Monthly Scientific, 2, 47-51 (2017)

7. P.E. Landolt, M. Sittig "Lithium", Ed. C.A. Hempel, Reinhold Publishing Corporation, New York, 16 (1961) 
8. Y.I. Ostroushko, P.I. Buchihin, V.V. Alekseeva, T.F. Naboyshchikova, G.A. Kovda and others, Lithium, its chemistry and technology, Publishing House "Atomizdat", Moscow, 321 (1960)

9. V.E. Plyushchev, B.D. Stepin, Chemistry and technology of compounds of lithium, rubidium and cesium, Publishing House "Chemistry", Moscow, 230 (1970)

10. S.L. Shvartsev, Hydrogeochemistry of the hypergenesis zone, Publishing House "Nedra", Moscow, 312 (1978)

11. A.P. Vinogradov, Geochemistry of rare and dispersed chemical elements in soils, Publishing House of AS of USSR, Moscow, 300 (1957) 